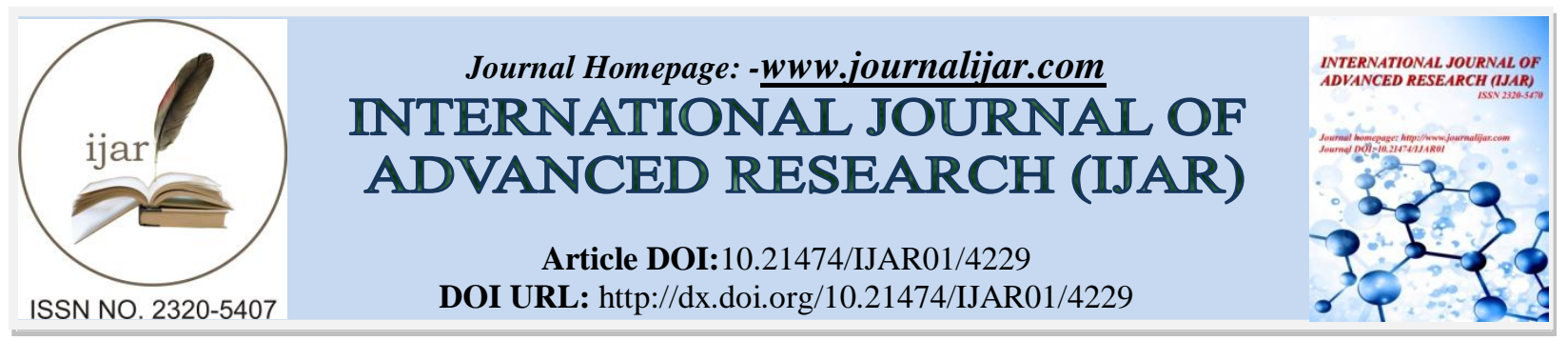

RESEARCH ARTICLE

\title{
A STUDY TO ASSESS THE PERCEPTION OF I M.B.B.S STUDENTS ON EVALUATION OF PRACTICALS IN UNDERGRADUATE CURRICULAM.
}

Dr. L. Santhanalakshmi.

\section{Manuscript Info}

Manuscript History

Received: 19 March 2017

Final Accepted: 22 April 2017

Published: May 2017

Key words:-

feedback, the students, mark distribution

and practical examination.

\section{Abstract}

The purpose of this session is to provide an overview of assessment, its importance in planning for curriculam reforms and faculty developments by obtaining feedback from the students regarding mark distribution in the practical examination.

\section{Introduction:-}

There is a need for educational reforms by improving knowledge and skills in principles in education technology. Adult learning principles should aim at curriculam development, teaching, learning and student assessment.

Evaluation is the process by which students make judgements about the value of learning which is often complex and controversial which is obtained by feedback forms for daily sessional evaluation. It involves a wide range of issues like duration of practicals, mark distribution, evaluation from expert based to practitioner based, the role of check list, methodology of understanding concepts in practicals etc., It also helps to reinforce the importance of programme evaluation in quality assurance of faculty development programmes.

\section{Aim and Objectives:-}

1. To assess the perception of I MBBS students in non clinical subjects.

2. To assess the perception of I MBBS students in duration of practicals, mark distribution and understanding the subject and their knowledge gained with clinical relevance.

\section{Methodology:-}

After getting Institutional ethical clearance, 100 I MBBS students of Madurai Medical College, Madurai volunteered for the study.

A proforma regarding the marks allotted for the The Tamilnadu Dr.M.G.R. Medical University

I MBBS Practicals was distributed. The 40 marks were distributed as follows;

i. OSPE - 2 skilled stations $\quad-4$

ii. Haematology-- Major-10 and Minor -6

iii. Clinical Physiology--- CNS-10+ CVS / RS -5 and Chart discussion-5

The duration of practicals was for about 3 hours.

Questionnaire had the following details;

Name, Age in years, Sex, Medium studied in school. 


$\begin{array}{lll}\begin{array}{l}\text { Duration for Haematology practicals; } \\ \text { Duration for Clinical Physiology; }\end{array} & \begin{array}{l}1 \text { hour } \\ \text { 1 hour } \\ \text { Duration for OSPE ; }\end{array} & \begin{array}{l}\text { Adequate, Not Adequate, Suggestions } \\ \text { Adequate, Not Adequate, Suggestions }\end{array} \\ \begin{array}{l}\text { Majs distribution for Haematology--- } \\ \text { Major-10 and Minor -6 }\end{array} & & \begin{array}{l}\text { Adequate, Not Adequate, Suggestions } \\ \text { adequate, Not Adequate, Suggestions }\end{array}\end{array}$

\section{Observation:-}

\section{Table I:-}

Age distribution of participants-

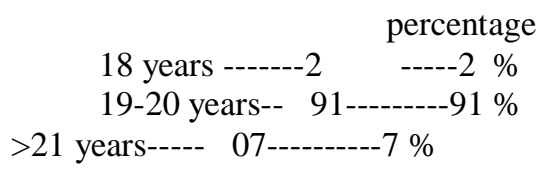

Table II:-

Sex; $\quad$ Male students $65 \quad$ Female students 35

Table III:-

Medium of Instruction and its impact in understanding the subject-

\begin{tabular}{lcccc} 
& \multicolumn{2}{c}{ Adequate } & Not adequate \\
English & 71 & \multicolumn{1}{c}{0} \\
Tamil & & 11 & & 05
\end{tabular}

Table IV:-

Perception of students regarding Duration for Haematology practicals for 1hour

Adequate ----87\%

Not Adequate------13\%

Table V:-

Perception of students regarding Duration for Clinical Physiology-

Adequate ----84\%

Not Adequate---16\%

Table VI:-

Perception of students regarding Duration for OSPE

Adequate ----32\% Not Adequate---68\%

Table VII:-

Perception of students regarding marks for Haematology practicals

Adequate ----88\% Not Adequate--- $12 \%$

Table VIII:-

Perception of students regarding adequacy of marks for Clinical Physiology

Adequate ----89\% Not Adequate--- $11 \%$

\section{Results:-}

The results were statistically analysed using Chi Square test.

The majority of I MBBS students perceived that duration and marks allotted for Haematology and Clinical Physiology by the The Tamilnadu Dr.M.G.R. Medical University is adequate. At the same time, many perceived that time and marks distributed for OSPE is totally inadequate.

\section{Discussion:-}

A medical Teacher has to be a lifelong learner by himself to keep upto date information in different fields. Evaluation plays a key role in providing useful inputs to the planners to improve the quality of the programmes and make them useful for the participants. Such evaluation needs to be focussed, specific and target the components which can be improved. At the same time, it should not be so long or so exhaustive. This feedback from the 
participants helps in reinforcing what was done well and suggests improvements for the components that can be changed.

The key concept of system approach is, any change in objectives demands a parallel change in examination and this demands a corresponding change in teaching methodology.

\section{Conclusion:-}

This project is based on the evaluation of feedback obtained from the students which conveyed the message that duration and marks allotted for the OSPE has to be modified for better performance. It indirectly enhances the knowledge and skill of the participants in learning and helps to understand the importance of effective feedback in formative and continuous assessement in learning. It also helps to improve the role and responsibility of the coordinators in planning Faculty development programme.

Evaluation means passing a value judgement on the quality or worth in relation to educational programmes.

\section{References:-}

1. Study at Adelaid Course Outline PHYSIO 3000 Lewy, School Attitudes; The International Encyclopedia of Education.

2. James M Curran University of South Florida, Sarasota-Manatee.

3. Deborah E Rosen University of Rhode Island.

4. MCI Regional centre for National Faculty Development, Christian Medical College, Vellore.

5. Principles of Medical Education by Tejender Singh,Piyush Gupta, Daljit Singh. 